\title{
ALN BUSINESS MODELS AND THE TRANSFORMATION OF HIGHER EDUCATION
}

Gary E. Miller

The Pennsylvania State University

Stephen Schiffman

Babson College and Franklin.W. Olin College of Engineering

\begin{abstract}
The ways institutions have structured their initial innovation with online learning vary greatly. Initial business model decisions present different challenges in terms of how institutions will integrate online learning. This paper looks at several common business models and the opportunities and challenges that each presents to institutions that want to fully integrate online learning.
\end{abstract}

\section{KEYWORDS}

Institutional Transformation, Access, Quality

\section{THE IMPACT OF STARTING POINTS}

Most institutions began their online learning programs with one of two goals in mind: (1) to extend access to degree programs to new off-campus students or (2) to improve the quality of teaching for existing students on campus. Initial emphasis on access or quality typically drove early decisions about organization and funding.

If access was the primary goal, institutions tended to position their online learning initiative within their continuing education or distance education programs. Examples from early Sloan Foundation projects include New York University, where the program operated within NYU's School of Continuing Studies; Penn State's World Campus, which is part of Penn State's Outreach organization; and the University of Maryland University College, which stands as a separate adult education institution in the University System of Maryland. While there are many different models for continuing and distance education among U.S. institutions and state systems, most share one common feature: they are organized as cost centers with the expectation that they recover costs of operations through new revenue generated by tuition and contracts. They also tend to report through separate university administrators rather than through academic deans.

If quality for on-campus students was the primary initial goal, institutions tended to position the online learning initiative within the Provost's office or in individual academic units. Examples include the University of Illinois, where the initiative tended to be more integrated into the traditional academic structure of the institution; programs were led by the Provost's office or by faculty in individual academic units. Cost recovery was achieved through the normal academic budget.

Regardless of where the institution started, online learning initiatives have tended to cross barriers. 
Traditional students have wanted to enroll in programs designed for external audiences; academic units have seen opportunities to extend campus-based online courses to off-campus audiences. The result has been to put pressure on the existing budget model and organizational structure.

\section{A. Access Models}

Institutions have innovated with online learning to extend access because they see an opportunity to generate revenue or because they see online learning as an extension of their social mission. Ideally, the two concerns overlap so that the social mission can be sustained. The two most common business models related to access are the creation of a for-profit subsidiary and the creation of a cost-recovery center (with varying degrees of central subsidy) within a continuing education unit.

\section{For-Profit Subsidiary Model}

The creation of a for-profit subsidiary within a nonprofit institution (public or private university) is perhaps the model with the highest risk for long-term success in U.S. online learning. Many for-profit subsidiaries have proven not to be sustainable. In some cases, the initial business opportunity was satiated, and the institution did not find additional avenues for growth or the intended market did not materialize. Since for-profit models tended not to be tied to the institution's core mission, there was little reason for internal investment to sustain the initiative. The for-profit approach presents significant challenges to full institutionalization, due largely to barriers between the for-profit work and the institution's nonprofit mainstream. For instance, if a faculty member wants to use intellectual property that he/she created in the for-profit unit with the faculty member's mainstream course-or if the institution wants to mingle external and internal students in a single course, it would need to develop new business processes to bridge the for-profit and nonprofit sides of the institution.

The leadership challenge for institutionalizing a for-profit subsidiary operation to transform the larger institution is to build bridges between the two business models. Connecting the two models may require internal licensing arrangements and new faculty policies. For example, a for-profit subsidiary may require separate intellectual property agreements with faculty for development of courses. Intellectual property agreements could limit the ability of faculty to integrate online courses into the nonprofit side of the institution. Similarly, the financial divide between a nonprofit institution and its for-profit subsidiary may make it impossible for the institution to mingle students from both sides of the institution into a single course section.

\section{Cost-Recovery Model}

The cost-recovery model is common among institutions that had a pre-existing commitment to continuing and distance education with an organizational infrastructure that could accommodate an online program. In this model, the online learning unit operates within the administrative structure of the larger institution, but functions as a separate budget center, with the goal of recovering its costs through new tuition revenue generated by new students. The challenge in this environment is to build new budget and administrative processes that allow mainstream students to participate in the continuing/distance education program. For example, most continuing education programs operate well outside the traditional bursar function of their institutions. A significant financial process issue arises when an online program created for external audiences is extended to traditional students. Paying for faculty time and effort (costs of teaching and/or

course development) is often another hurdle, as these activities are often not part of a traditional academic department's teaching load model. 


\section{B. Quality Models}

Some institutions have used online learning to address quality and cost issues within the institution's mainstream resident program. In this context, "quality" may relate primarily to instructional issues: the desire to improve interactivity in large lecture sections or to encourage greater levels of student inquiry and knowledge creation in a course. Ensuring curricular coherence across multiple sections of a course may also be seen as a quality issues. Cost issues may relate to reducing the drop-out rate in high-enrolling courses and minimizing the need for duplicate sections of a course.

In these situations, institutional leaders have three primary challenges: (1) how to sustain the cost of online learning within the existing tuition stream; (2) how to move from the limited scope of an innovation (often supported by a grant or contract) to a broader institutional strategy; and (3) how to organize centralized support services for development and delivery so that all academic units have appropriate access to online learning. These challenges speak to broad institutional cultural issuesfaculty ownership of their individual course content, for example - on one hand and "backroom" business process issues - the need to reserve funds annually from tuition, research funding and state appropriations income to support the development, maintenance, and assessment of online courses — on the other.

\section{LIMITS TO GROWTH}

The initial business model provides a starting point for institutions to consider mainstreaming the online learning initiative. Each institution must consciously recognize and select the appropriate model that fits its mission and culture and work to implement that model as effectively and efficiently as possible. Next steps depend on how far along the institution is in developing its capabilities in the area of online education. If an institution has developed significant capabilities, it is time to re-examine core strategies for the institution as a whole, to begin the process of integrating strategies. Conversely, unless an institution has achieved some meaningful level of learning about how online education fits it, higher level integration is premature.

Mintzberg uses the metaphor of the potter who learns by experience what is possible to craft with clay. Experience determines the final form of the object. By analogy, institutional strategy also should emerge as a function of experience; strategy is crafted by hands and minds, not just by pure logic. Strategy must be consistent with the institution's mission. As long as an institution's mission for distance education is seen as unconnected with the mission as a whole, transformation is not likely. Equally important, the strategy must be consistent with the institution's culture; to a great extent, the institution's experience during the period of initial innovation is a test of cultural acceptance. As Mintzberg noted, "Strategies grow like weeds in a garden. They take root in all kinds of places, wherever people have the capacity to learn (because they are in touch with the situation) and the resources to support that capacity. These strategies become organizational when they become collective, that is, when they proliferate to guide the behavior of the organization at large” [1].

The relevance to educational institutions pursuing online educational initiatives is obvious. The right thing to do at the start is to pursue the Sloan-C 5 pillars of quality [2], within a suitably chosen business model. As some point, however, the institution becomes ready to craft a new strategy, to integrate its capabilities in online education into the strategy of the institution as a whole—or set it aside.

The process of optimizing the online educational subsystem leads to what may be termed "constrained (or local) maxima.” To illustrate, think of fixed pegs and attached ropes. Think of the existing institutional structures (policies, procedures and organization) as fixed pegs. Other pegs represent external structures: 
accrediting agencies and political structures. To these pegs are attached a network of ropes representing the people and initiatives of the institution. The pegs are there for a good reason (or at least they were, presumably, at some time): to give the moving ropes a measure of stability. Policies, procedures and organization are artifacts of strategy that guide people and initiatives in alignment with institutional mission. In whatever way the online educational initiative is positioned in an institution, as a separate unit or "virtual" organization [3], its running room is constrained by the fixed pegs of institutional structures. In its quest for continual improvement, then, at some point the institution reaches its limit of stretch. This is a local or constrained maximum.

An example specific to ALN may be useful in understanding this concept. Suppose an institution started online education with access as a primary goal, organized within a continuing education program, and used adjunct and some full-time faculty to deliver courses, paying them on an "overload" basis. No matter how efficient this process becomes, it does nothing to advance the understanding of how to "mainstream" online education within the full-time faculty workload process (usually accomplished through the academic departments), should that become a desired direction for the institution to take.

\section{INSTITUTIONAL TRANSFORMATION}

Mainstreaming online learning within an institution will require vision and leadership on both the administrative and academic sides of our institutions. Many of the most important short-term issues are administrative: how to fund course development; how to support the new needs for technical help and other student support issues; how to ensure a flow of resources back to academic units that take faculty members from their regular teaching to reach out to online learners; how to decide what services should be supported centrally and what should be provided locally; how to deal with the breakdown of traditional areas of administrative authority and "turf" as innovation is diffused throughout the institution.

Other issues, however, strike at very important academic issues: how to recognize faculty contributions when their individually authored content is shared by other faculty; how to champion a new pedagogy; how to effectively assess and evaluate all aspects of the performance of online courses; how to hold faculty members accountable for their use of online materials in a blended environment; how to ensure curricular coherence across sections of a course or across campuses.

Institutions that have made their online learning management system ubiquitous for faculty and students alike-rather than a restricted-access tool available only for formal instruction-have seen a rapid acceptance of the online environment for co-curricular activities (informal discussion groups, student clubs, professional societies, etc.). This extension is part of the mainstreaming process and raises additional questions about how to fund and support the co-curricular infrastructure without hindering the quality of delivery for formal instruction.

\section{A. Defining a Transformation Community}

While any major change requires leadership, institutionalizing change cannot be accomplished by one person working in a vacuum. Transformation requires a community of people in different parts of the institution, each with their own advocacy role, their own contribution to mission, and their own sense of ultimate ownership. 
Constituencies that need to be involved in the transformative process, and benefits, are:

\begin{tabular}{|l|l|l|}
\hline Constituency & What can be Transformed & Key Benefits \\
\hline Faculty & $\begin{array}{l}\text { Scholarship, Educational } \\
\text { Programs }\end{array}$ & $\begin{array}{l}\text { Time-to-market for educational } \\
\text { programs, } \\
\text { Wider markets for high quality } \\
\text { educational programs, } \\
\text { Faculty collaborations }\end{array}$ \\
\hline $\begin{array}{l}\text { Executive/Middle-level } \\
\text { Administration }\end{array}$ & $\begin{array}{l}\text { Systems, Policies, Procedures, } \\
\text { Resource Allocation }\end{array}$ & $\begin{array}{l}\text { Reformed mission and core values, } \\
\text { More effective development and } \\
\text { implementation of education }\end{array}$ \\
\hline External & $\begin{array}{l}\text { Boards (private and public), } \\
\text { Political Bodies (e.g. legislatures), } \\
\text { Accreditation Bodies }\end{array}$ & $\begin{array}{l}\text { Improved institutional accountability, } \\
\text { standards, congruent with improving } \\
\text { education }\end{array}$ \\
\hline
\end{tabular}

Table 1. Constituencies in Transformation Community

Community involvement at all levels of the organization or system is a key for successful transformation. The role of executives during periods of incremental change is different than it is during transformational times. During periods of incremental change, executives reemphasize mission and core values, delegating incremental decisions to middle-level managers: "The overall system adapts, but is not transformed” [4].

Middle-level managers also play a crucial role. Sayles points out that "middle managers often become the players who can facilitate necessary trade-offs among the diverse parts of any work system" and "it takes a middle manger to get senior management's attention and make the case for change” [5].

To accomplish institutional transformation, members of the community will need to acquire new skills and information, or hone existing skills, including: leadership, strategic planning, building a shared vision, communication, systems thinking, and networking.

\section{B. The Transformation of Higher Education}

The movement of online learning from the beginning of innovation to the complexity of a college of university mainstream involves many different aspects of the institution's culture and is at the core of its mission. During the innovation phase of online learning, the emphasis is on the experiences and performance of individual faculty members and students and on how to sustain a program over time. As online learning enters the mainstream, these considerations are joined by broader concerns over core administrative and financial processes, fundamental questions of pedagogy, and, as many institutions are seeing, challenges to traditional assumptions about who does what within the institution, about what decisions and services are centralized and what are decentralized, and, ultimately about who we serve and how we support them. Mainstreaming this innovation is transformative.

Moreover, the transformation is not driven only by internal decisions. As we move into the second generation of the Information Revolution, the external demands on our educational institutions are changing. Increasingly, students come to our institutions expecting to use technology, expecting to collaborate online, expecting to challenge faculty ideas by "googling” them during class and IM'ing fellow students with the results. Increasingly, adult professionals understand that they need recurring access to formal education throughout their careers and expect to be able to have access without giving up their jobs and moving their families to the institution that can best meet their needs. Increasingly, 
employers expect their staff to be able to work in a virtual environment, expect them to function effectively in online global working teams and learning communities. Increasingly, communities expect their universities to educate students to be effective citizens in an information society.

The challenge is being able to enter into completely new and innovative partnerships and business relationships with other institutions of higher learning world-wide as well as with traditional businesses and vendors.

The ultimate transformation of higher education will be determined by how well institutions mainstream online learning into their curricula, into their business practices, and into the broad academic culture of their institutions in order to respond to these external demands.

\section{QUESTIONS TO CONSIDER ABOUT ALN BUSINESS MODELS AND INSTITUTIONAL TRANSFORMATION}

1. What was your primary institutional goal for initial engagement in ALN: to extend access or to improve quality?

2. What business model was chosen to implement ALN: within continuing education or distance learning, under academic departments or the provost's office, or some other model? How well matched was the business model to attaining your initial institutional goals for ALN?

3. As you have gained experience in ALN, how have your goals expanded and/or changed? Have these new goals been institutionalized? How well are they understood throughout the institution as a whole?

4. What institutional policies, procedures or structures present challenges in meeting your new goals? Is the business model for ALN still well suited?

5. What key members of your institutional community, at various levels and functions, should constitute the ideal team to lead institutional transformation through ALN?

6. What new skills and information do individuals on this leadership team need in order to effect change?

\section{REFERENCES}

1. Mintzberg, H. Crafting strategy. Harvard Business Review: July-August 1987.

2. The Sloan Consortium: Pillars of the Quality Framework: http://www.sloan-c.org/effective /framework.asp.

3. Schiffman, S. Business issues in online education. In: J. Bourne and J. C. Moore (Eds.), Elements of Quality Online Education: Engaging Communities, Volume 6, 149-172. Needham, MA: Sloan-C, 2005.

4. Tushman, M., W. Newman, and E. Romanelli. Convergence and upheaval: Managing the unsteady pace of organizational evolution. California Management Review: Fall 1986.

5. Sayles, L. Doing things right: A new imperative for middle managers. Organizational Dynamics: Spring 1993. 


\section{ABOUT THE AUTHORS}

Gary E. Miller is Associate Vice President for Outreach at The Pennsylvania State University, where he serves as Executive Director of Penn State Continuing and Distance Education. He was the founding Executive Director of Penn State World Campus, the University's online distance education program. Dr. Miller is the author of The Meaning of General Education: The Emergence of a Curricular Paradigm and numerous journal articles and book chapters on distance education and the undergraduate curriculum.

He currently serves on the board of directors of the American Distance Education Consortium (ADEC) and the Sloan Consortium (Sloan-C). In 2004, he was inducted into the International Adult and Continuing Education Hall of Fame. He received the 2004 Weidemeyer Award from the University of Wisconsin and The American Journal of Distance Education for his contributions to distance education.

Stephen Schiffman is associate professor of entrepreneurship at both Babson College in Wellesley, Massachusetts and the Franklin.W. Olin College of Engineering in Needham, Massachusetts. He was dean of the undergraduate program at Babson from 1994-2002. As dean, he was architect of the new Babson undergraduate curriculum which was launched in 1996. In 1997 the Pew Charitable Trusts recognized this effort by selecting Babson for a Pew Leadership award for renewal of undergraduate education, and in 2002 Babson was awarded the TIAA-CREF Hesburgh award for Reinvention of Undergraduate Curriculum. Steve holds a Ph. D. in mathematics from Dartmouth College as well as an M.S. in Management and a B.S. in mathematics from M.I.T. He taught at the University of Colorado and Colorado College, and prior to coming to Babson, he worked at Digital Equipment Corporation. Email Stephen.schiffman@olin.edu. 